\title{
Using short deflections in evaluating a narrow tabular UG2 Reef platinum group element mineral resource
}

\author{
by J. Witley*† and R.C.A. Minnitt ${ }^{*}$
}

\section{Synopsis}

Narrow tabular platinum group element deposits in the Bushveld Complex of South Africa are typically evaluated by diamond core drilling from surface. Several short deflections are drilled from each mother hole in order to obtain multiple intersections at a close spacing (less than $1 \mathrm{~m}$ ). Examination of the intersections from deflection drilling revealed the importance of these deflections in understanding the representivity of the borehole, obtaining an estimate of the nugget effect, and mitigating the undesirable effect of the high grade variability at the ultra-short range that is a characteristic of these deposits. The use of deflections in estimation was investigated by means of a number of techniques and scenarios in order to find the most appropriate way to use them in an estimate. A significantly improved level of confidence was gained from using multiple close-spaced intersections rather than a single borehole intersection.

Keywords

resource evaluation, deflection drilling, grade variability, nugget effect.

\section{Introduction}

The Upper Group 2 chromitite layer (UG2 or UG2 Reef) is known for its remarkable geological continuity, being traced almost uninterrupted for tens of kilometres. However, what is often less well emphasized is the high variability in platinum group element (PGE) grade and thickness (and therefore PGE content) and internal reef stratigraphy over very short distances (several metres or even tens of centimetres).

This paper examines the application of short drill-hole deflections in evaluating UG2 PGE mineral resources at Marikana in the western Bushveld Complex of South Africa.

\section{Sources of variability in the UG2 Reef morphology}

At Marikana, the UG2 Reef normally comprises a massive chromitite layer, which is generally between $0.9 \mathrm{~m}$ and $1.4 \mathrm{~m}$ thick. The thickness and PGE grade gradually change from one area to the next over the $27 \mathrm{~km}$ strike length of the property.

The hangingwall to the UG2 Reef is pyroxenite, the top contact being sharp and planar. In contrast, the lower contact with the underlying pegmatoidal pyroxenite, norite, or anorthosite is irregular, with the chromite forming cuspate and even carrot-like protrusions into the underlying lithologies over distances of tens of centimetres (Figure 1). Localized areas of internal waste can occur, and the internal waste is necessarily included in the mineral resource.

The UG2 is disturbed by geological conditions such as potholes, faults, intrusive dykes, and iron-rich ultramafic pegmatite (IRUP). Faulted intersections can normally be identified easily, as can areas of IRUP, which tend to form geological domains on the scale of several hundred metres to one or two kilometres. Potholes are ubiquitous features that affect the UG2. These are more problematic as they occur in a seemingly random fashion and pothole edges can appear as normal UG2 in a single intersection (Figure 2). Potholes are in the order of metres to hundreds of metres in scale, although at Marikana approximately $80 \%$ are less than $2000 \mathrm{~m}^{2}$ (approximately $50 \mathrm{~m}$ in diameter; Hoffmann, 2010).

When estimating UG2 mineral resources, intersections affected by local geological disturbances are not used in grade estimation unless they form a distinct domain, such as large areas affected by IRUP. A block estimate is often conducted with a small number of widely spaced boreholes with the aim of evaluating a large block of ground (typically $500 \mathrm{~m}$ by $500 \mathrm{~m}$ ). The disturbed intersections represent a small area relative to the estimation block and are removed from the estimation data so that they do not disproportionally impact the estimate. Disturbed areas are not mined and are attributed to geological losses that are applied to the model as a factor

* School of Mining Engineering, University of the Witwatersrand, South Africa.

+ The MSA Group, Victory Park, Johannesburg, South Africa.

(c) The Southern African Institute of Mining and Metallurgy, 2017. ISSN 2225-6253. Paper received Apr. 2016; revised paper received Jan. 2017. 


\section{Using short deflections in evaluating a narrow tabular UG2 Reef}

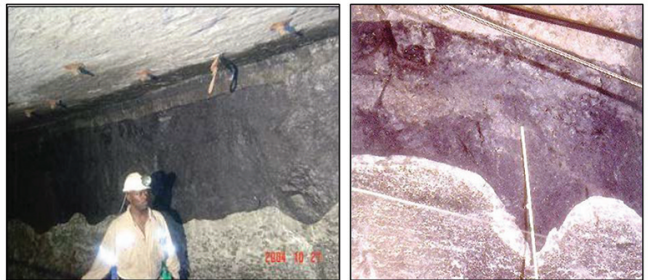

Figure 1-Examples of high footwall variability in the UG2 Reef, illustrating high relative short-range variability in thickness (courtesy of Lonmin)
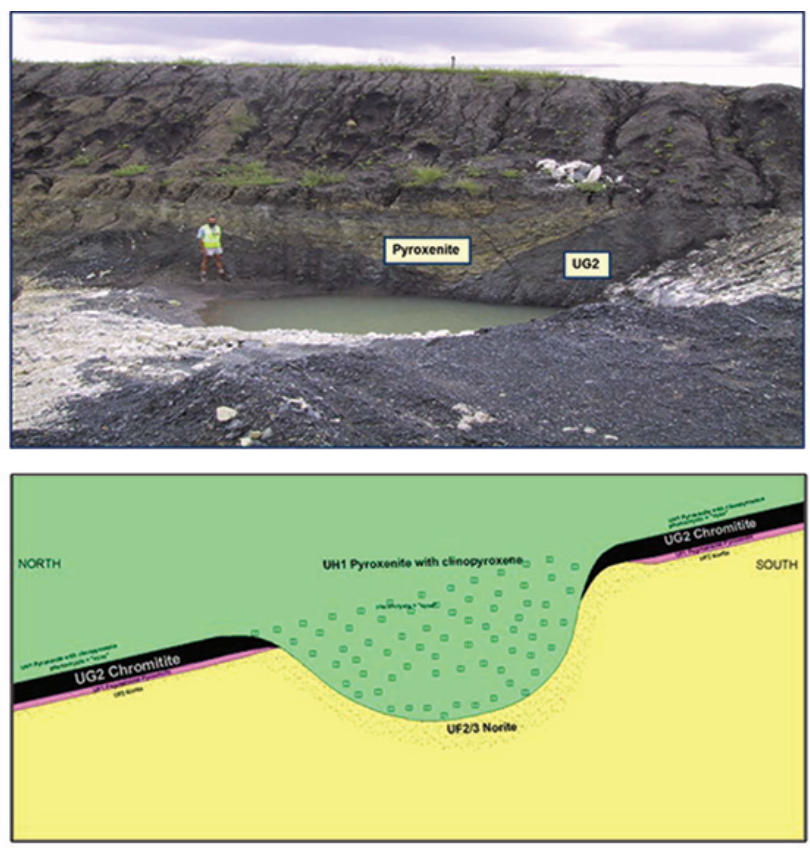

Figure 2-Photograph and schematic representation of UG2 potholes (courtesy of Lonmin)

to estimate the quantity of mineral resources. It is important to identify these disturbances so that an accurate estimate, without using invalid intersections, is made.

The UG2 Reef dips to the north at between $8^{\circ}$ and $14^{\circ}$, although it can vary more than this, particularly in the vicinity of geological disturbances.

\section{Borehole drilling}

Diamond drilling of boreholes is conducted predominantly from surface down through the Merensky and UG2 Reefs until several tens of metres into the footwall lithologies. The reef is first drilled through by a BQ-size mother hole using wireline drilling techniques. The $\mathrm{BQ}$ core is of relatively small diameter $(36.4 \mathrm{~mm})$ and is kept as the reference core for the hole and is not normally sampled. Once the depth of the reef down the hole has been defined by the mother hole, a number of TBW-size deflections are drilled through the reef using conventional drilling techniques. The TBW-size core is larger diameter than BQ; $44.9 \mathrm{~mm}$ in diameter.

Deflection intersection drilling is accomplished by inserting a one-degree wedge into the mother hole, which deflects the drill bit to one side and provides for additional reef intersections a short distance away. At Marikana, three deflections are drilled using wedges inserted first at $5 \mathrm{~m}$, secondly at $10 \mathrm{~m}$, and then thirdly at $15 \mathrm{~m}$ above the reef hangingwall position. Once these three deflections have been drilled, a fourth deflection (stored for destructive metallurgical or geotechnical test work) is drilled out of the hole formed by the third deflection from $5 \mathrm{~m}$ above the reef hangingwall position. Deflection drilling continues by inserting further wedges until four complete and representative cores of the reef intersection are obtained. Reef intersections that are badly broken or suffer core loss through poor drilling practice or broken ground are rejected.

The short deflections provide a cluster of intersections a short distance away from each other. In a normal fourdeflection situation, assuming the wedges were positioned as mentioned previously, the maximum distance of the fourth intersection from the mother hole is approximately $0.35 \mathrm{~m}$ (Figure 3). Figure 4 shows the relative positions of the deflection holes to each other as exposed underground. In this borehole, the reef was intersected by the deflection holes at distances approximately $6 \mathrm{~cm}$ and $35 \mathrm{~cm}$ apart.

The cores are marked up for sampling using a standard pattern and layer coding (Figure 5). Cores are cut in half longitudinally; one half is used for assay and the other kept for reference or for future check sampling. The samples are weighed in air and water for specific gravity determination at the core yard and then sent to an independent accredited laboratory for PGE analysis as well as for a variety of other elements.

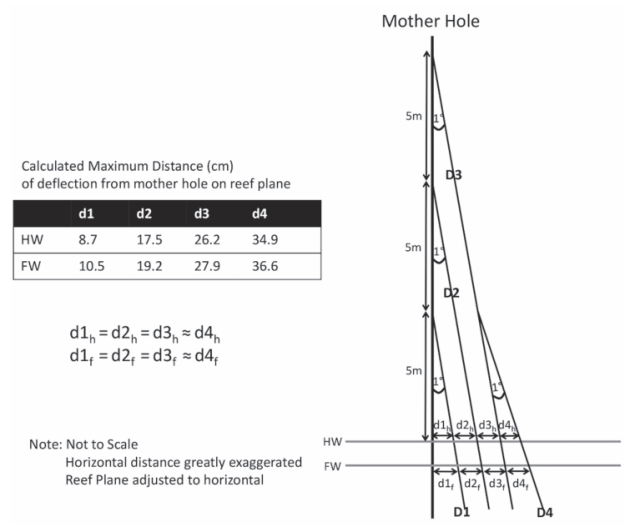

Figure 3-Illustration of maximum theoretical intersection spacing in the reef plane for a normal four-deflection situation

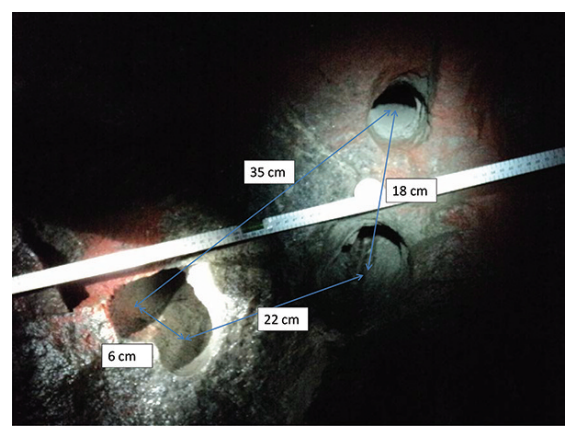

Figure 4-Photograph of actual intersection of borehole RS111 exposed in a raise at the K4 Shaft (view is looking approximately upwards into the hangingwall) 


\section{Using short deflections in evaluating a narrow tabular UG2 Reef}
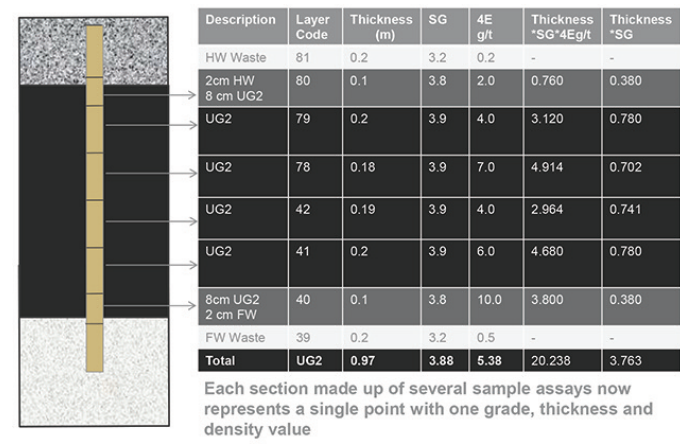

Each section made up of several sample assays now represents a single point with one grade, thickness and density value

Figure 5-Illustration of a typical sample pattern for UG2 Reef and the compositing calculation that is used to produce a single $4 \mathrm{E}$ and thickness value for each reef intersection

For convenience, PGE grades are typically combined to $4 \mathrm{E}$ (the summation of platinum, palladium, rhodium, and gold) or $6 \mathrm{E}$ ( $4 \mathrm{E}$ plus ruthenium and iridium).

\section{Using deflection intersections to identify short-range geological and grade variability}

The borehole data within the study area consists of data for 400 boreholes drilled from surface. Geological disturbances in borehole core can be subtle and difficult to recognize on the basis of a single deflection. The practice of drilling multiple deflections provides a means to identify boreholes affected by geological disturbances that might otherwise be missed on the basis of a single intersection. The validation process is as follows:
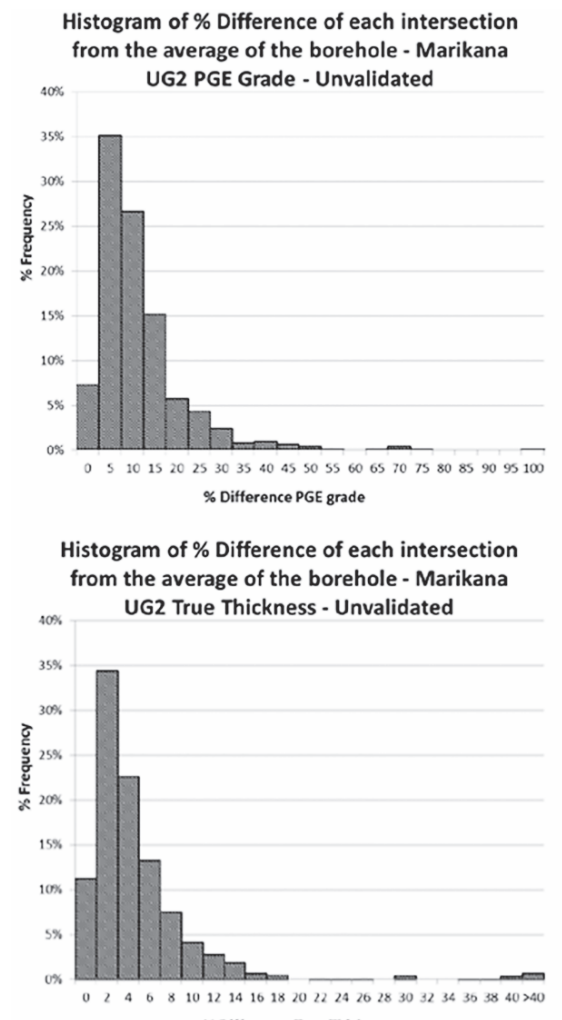

$\%$ Difference True Thickness
> Samples are composited into a single 4E grade and thickness value for each intersection (Figure 5)

> Lateral composites for each borehole are calculated so that the grade and thickness of the deflection composite intersections are averaged into a single value for the borehole, and the variance is calculated

> The percentage difference between each intersection and the borehole average is calculated for PGE grade and intersection true thickness

> Intersections with a large difference from the mean borehole value and boreholes with high betweenintersection variance are examined for geological disturbances such as faulting and potholing, as well as for possible data errors.

Histograms showing percentage difference between the deflection intersection and the average borehole value for PGE grade and true thickness are positively skewed with a long tail (Figure 6). The tail values were examined and geological disturbances were identified in 30 boreholes, which is equivalent to approximately $7.5 \%$ of the borehole data-set. By examining the boreholes with high variance, seven intersections with data errors were identified. The errors were later corrected in the database and included in the study data-set. After the invalid intersections were removed the histograms had shorter tails, the outlier data being rectified or discarded when found to be invalid (Figure 6).

The lateral composite validation approach is a useful tool in determining whether a borehole intersection is representative. The effects of potholes are often subtle and potholes may not be easily identifiable during logging. The increased variability over short distances apparent in potholed reef is often identified in multiple deflections by changes in the
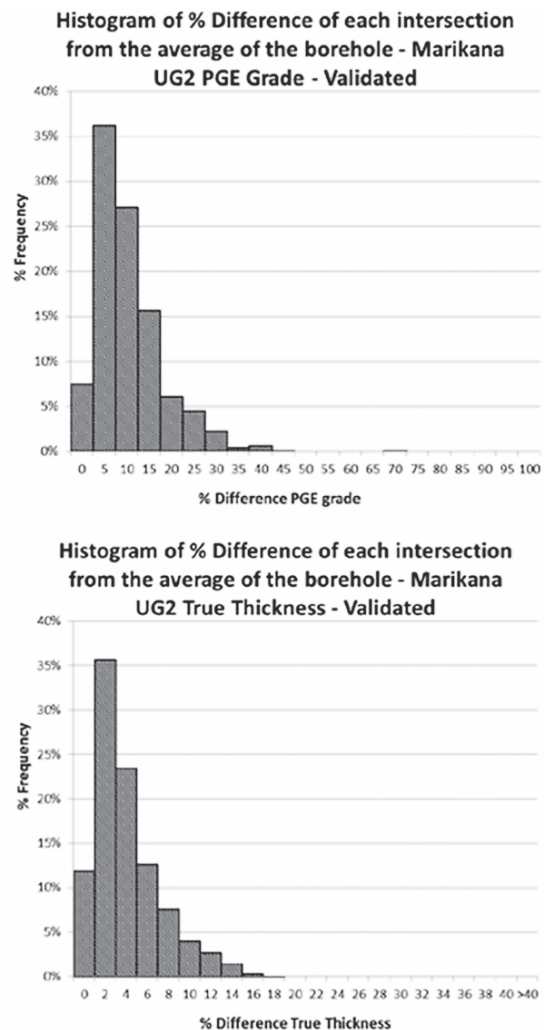


\section{Using short deflections in evaluating a narrow tabular UG2 Reef}

internal stratigraphy, such as the amount of internal pyroxenite or anorthosite, large thickness variations, varying grade distribution between deflections, and irregular core angles.

The use of a single borehole intersection from a widely spaced grid, rather than a cluster of deflection intersections for each borehole, exposes the estimate to high risk, the single intersection not being a good indication of the grade or thickness of a small area (less than $1 \mathrm{~m}$ ) represented by the borehole deflections. An error is introduced by extending the grade of the sample (or samples) to that of the area (Krige, 1981), which is considerable for the small area of each UG2 borehole covered by the deflections. The risk in using only one intersection is illustrated by comparing the grades and thicknesses of five valid borehole intersections (Table I). In each borehole a single deflection intersection PGE grade is considerable different from its neighbours, yet their distance apart is negligible, thus highlighting the high nugget effect semivariance and the risk in an estimate should only one deflection intersection be available. The differences between the grades of intersections in one borehole are as high as the differences in grades between the boreholes. The impact is generally less severe for true thickness, although in some cases it is considerable. As a result of the high PGE grade variability between deflection intersections, a high nugget effect semivariance may be expected.

\section{Use of multiple intersections to calculate the nugget effect}

A central area of Marikana was selected for the study. The UG2 stratigraphy in this area is the simplest and there is a large amount of relatively closely spaced (between $10 \mathrm{~m}$ and $40 \mathrm{~m}$ ) channel sample data. The channel samples were collected by cutting channels in the reef with a diamond saw to produce samples with similar mass per metre to a borehole sample.

Table I

Deflection intersection values and average for each borehole for a selection of five boreholes

\begin{tabular}{|l|c|c|c|}
\hline Borehole & Deflection & PGE (g/t) & True thickness (m) \\
\hline A & D1 & 4.97 & 0.94 \\
& D2 & 5.76 & 0.96 \\
& D3 & 7.87 & 1.03 \\
\hline B & Average A & 6.25 & 0.98 \\
\hline & D1 & 9.28 & 1.18 \\
& D2 & 7.23 & 1.09 \\
& D3 & 7.04 & 1.07 \\
C & Average B & 7.89 & 1.11 \\
& D1 & 6.27 & 0.92 \\
& D2 & 7.98 & 0.97 \\
& D3 & 6.25 & 0.91 \\
D & Average C & 6.86 & 0.93 \\
& D1 & 6.09 & 1.04 \\
& D2 & 4.99 & 1.05 \\
& D3 & 6.13 & 1.03 \\
\hline E & Average D & 5.73 & 1.04 \\
\hline & D1 & 7.30 & 0.99 \\
& D2 & 5.57 & 0.98 \\
& D3 & 5.34 & 1.00 \\
& Average E & 6.07 & 0.99 \\
\hline
\end{tabular}

The channel samples were composited in the same manner as the borehole samples (Figure 5). A semivariogram was calculated and modelled on the channel sample composite data.

When calculating the experimental semivariance, the composite sample data was set to zero elevation and semivariograms were calculated in a two-dimensional plane. Traditional omnidirectional semivariograms were calculated, as no anisotropy was identified. Normalized semivariograms were used whereby the sill is set to unity relative to the estimated sample variance.

The experimental semivariogram data was modelled with three spherical structures and a nugget effect for both true thickness and $4 \mathrm{E}$ grade (Figure 7). The deflection data was used to calculate the nugget effect as a proportion of nugget effect variance to total variance of the borehole data. This was found to be $56 \%$ of the total variance for $4 \mathrm{E}$ grade, and $17 \%$ for true thickness. Only assays using fire assay and lead collection were considered, as those using other methods (such as nickel sulphide collection) have a different precision, which will impact on the 'untrue' nugget effect component.

The nugget effect obtained from deflection intersections is more correctly the semivariance of a short-range structure. As pointed out by Clark (1979), 'two samples measured at exactly the same position must have the same value'. Matheron (1971) described the nugget effect as a transition phenomenon that can have a range of the order of centimetres, and emphasized the importance of scale. Krige (1981) pointed out that it can readily be visualized that in the extreme case of a point sample, a minute change in the position of the point can result in a substantial difference in the actual grade, due to the presence or absence of minute metal particles, and he mentioned the additional contribution of sampling and assaying error to the nugget effect. Carrasco

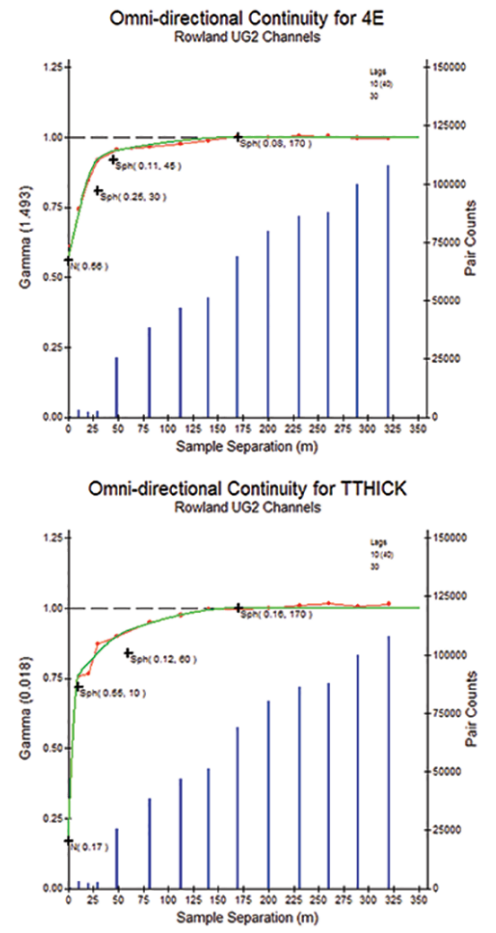

Figure 7-Semivariograms for 4E grade and true thickness - Marikana study area 


\section{Using short deflections in evaluating a narrow tabular UG2 Reef}

(2010) noted that the magnitude of the nugget effect is very dependent on sample support, sampling density, sampling quality, assaying procedures, and the nature of the phenomenon under study, and also pointed out the importance of scale. Pitard (1993) ascribes the geostatistical nugget effect to two different components, also noting the importance of scale:

> 'true in situ' nugget effect (i.e. small-scale intrinsic variability of the grade, or 'chaotic component')

> a number of variability components due the various aspects of sampling and sample preparation and assaying procedures ('untrue' nugget effect).

True thickness nugget effect can only be an ultra-shortrange structure, there being no 'untrue' nugget effect component, the cause of the nugget effect value being clear when examining the variability over a few centimetres in mining exposures as shown in Figure 1.

In platinum mining operations, channel samples are typically tens of metres apart and boreholes are normally hundreds of metres apart. Considering the scale of the sampling, the semivariance estimated from the deflection intersections is, in the authors' opinion, a reasonable proxy of the nugget effect from a geostatistical point of view. As pointed out by Clark (2010), assigning nugget effect to a short-range structure counterintuitively gives a higher kriging variance than if it was dealt with as 'true' nugget effect.

Although the nugget effect for $4 \mathrm{E}$ grade makes up a large proportion of the total variance, the total variance $(1.493$ $\left.\mathrm{g} / \mathrm{t}^{2}\right)$ is low. Continuity is demonstrated for up to $170 \mathrm{~m}$; however, $92 \%$ of the variance has been accounted for in the first $45 \mathrm{~m}$. The range of the true thickness semivariogram is similar to that of $4 \mathrm{E}$ grade, although the nugget effect contributes to only $17 \%$ of the variance and the longer range portion of the semivariogram accounts for a larger proportion of the variance than $4 \mathrm{E}$ grade. Given the lower variance of the thickness data, estimates of thickness will be more accurate than those of $4 \mathrm{E}$ grade using the same number of composite samples.

It is noteworthy that the semivariograms obtained from channel samples demonstrate that the continuity of grade and thickness is less than is implied by the geological continuity for which the UG2 is well known. There is a large random component to the variability, rather than a spatial component, as indicated by the deflection intersections.

\section{Multiple intersections from deflections in estimation}

Multiple intersections drilled from the same borehole are used in a number of ways. They provide an estimate of the nugget effect, they de-risk a borehole, they are used directly in grade estimation, and they provide important information on geological variability over short distances, which may identify non-representative boreholes.

\section{Sensitivity of nugget effect to number of deflections}

In order to understand how many boreholes are required to obtain a robust estimate of the nugget effect, the following test was carried out:

> The nugget effect for both true thickness and PGE grade for deflections was calculated only for the boreholes that had three sampled deflection intersections

> The nugget effect was calculated for the total data-set, and again by successively reducing the number of boreholes by ten. In this way the differences in the nugget effect due to using fewer and fewer boreholes could be assessed

> Ten iterations of the nugget effect were calculated for each reduced number of data by selecting different combinations of boreholes in the reduced data-set using a random number generator.

Plots showing the nugget effect versus the number of boreholes used for each of the iterations are shown in Figure 8 . The nugget effect plus or minus $10 \%$ and $20 \%$ of that calculated using the total data-set for three deflections is shown on the plots. These demonstrate that the nugget effect is sensitive to the number of boreholes used. Only when 50 boreholes are used, each with three deflections, does the nugget effect stabilize within $\pm 20 \%$ of the total data estimate.

\section{Estimate of error in a borehole}

The nugget effect of the semivariogram can be used to assess the error in the grade of the borehole calculated from its deflections. If it is assumed that the deflection values vary randomly from the 'true' borehole values, the error is calculated using the $t$ statistic as follows:

$$
t_{n-1 ; 0.05} \times S_{C 0} / \sqrt{n}
$$
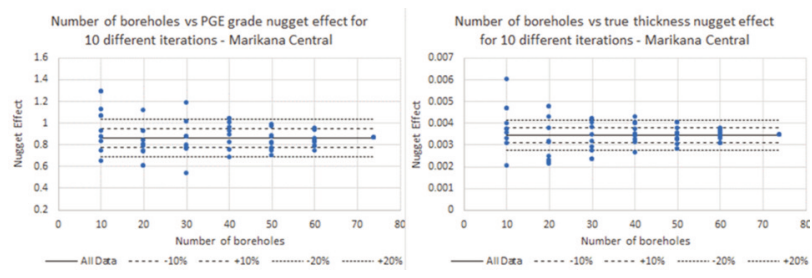

Figure 8-Sensitivity of nugget effect to number of boreholes - three deflections. PGE on left, true thickness on right

Table II

Semivariogram parameters for Marikana study area UG2

\begin{tabular}{|c|c|c|c|c|c|c|c|}
\hline Attribute & $\begin{array}{l}\text { Nugget effect } \\
\text { (CO) }\end{array}$ & $\begin{array}{l}\text { Range of first } \\
\text { structure (R1) }\end{array}$ & $\begin{array}{l}\text { Sill } 1 \\
\text { (C1) }\end{array}$ & $\begin{array}{c}\text { Range of second } \\
\text { structure (R2) }\end{array}$ & $\begin{array}{l}\text { Sill } 2 \\
\text { (C2) }\end{array}$ & $\begin{array}{l}\text { Range of third } \\
\text { structure (R3) }\end{array}$ & $\begin{array}{l}\text { Sill } 3 \\
\text { (C3) }\end{array}$ \\
\hline $\begin{array}{l}4 \mathrm{E} g / \mathrm{t} \\
\text { True thickness } \\
4 \mathrm{E} \mathrm{cmg} / \mathrm{t}\end{array}$ & $\begin{array}{l}0.56 \\
0.18 \\
0.54\end{array}$ & $\begin{array}{l}30 \\
10 \\
20\end{array}$ & $\begin{array}{l}0.25 \\
0.55 \\
0.23\end{array}$ & $\begin{array}{l}45 \\
60 \\
40\end{array}$ & $\begin{array}{l}0.11 \\
0.12 \\
0.15\end{array}$ & $\begin{array}{l}170 \\
170 \\
170\end{array}$ & $\begin{array}{l}0.08 \\
0.15 \\
0.08\end{array}$ \\
\hline
\end{tabular}




\section{Using short deflections in evaluating a narrow tabular UG2 Reef}

where:

$t_{\mathrm{n}-1}=$ the percentage points of the $t$ distribution at various degrees of freedom

$S_{C O}=$ the nugget effect standard deviation

$n=$ the number of intersections in each borehole.

The error was calculated for different numbers of intersections for PGE grade as well as for true thickness (Figure 9).

A significant decrease in the error is noticeable when the number of deflections is increased from two to five. An increase in the number of deflections from two to three results in the error being more than halved, and a reduction in error of approximately $30 \%$ is experienced when the number of deflections is increased from three to four. The true thickness error is less than $10 \mathrm{~cm}$ (around 10\% relative error) when three deflections are available, but the PGE grade error is over $1 \mathrm{~g} / \mathrm{t}$ (around 20\% relative error). Should four deflections be drilled and assayed instead of three, the PGE grade error would reduce from $1.07 \mathrm{~g} / \mathrm{t}$ to $0.74 \mathrm{~g} / \mathrm{t}$, resulting in a relative error of approximately $15 \%$ should the PGE grade of the borehole be $5 \mathrm{~g} / \mathrm{t}$.

In addition to the error calculation, the benefit of each additional deflection can be simplistically judged by the weight assigned to the deflection. As the number of deflections increases the relative weight assigned to each will necessarily decrease, as illustrated in Figure 10.

The relative kriging weight of each deflection reduces rapidly as more deflections are used. Once more than five deflections are available, little additional benefit to the estimate is gained.

\section{Use of deflections in estimation}

Deflections drilled from mother holes at Marikana result in a number of reef intersections separated by short distances, from a few centimetres to several tens of centimetres. The deflection holes are not surveyed down the hole and the wedges themselves are not inserted in any particular direction (non-directional wedges). When estimating mineral resources using the intersections obtained through deflection drilling, assumptions need to be made about the distance and direction of the intersections from one another. An alternative to using individual deflection intersections is using lateral composites.

A method of dealing with non-directional deflections is to add a nominal distance of $20 \mathrm{~cm}$ to each deflected intersection in a clockwise direction, so that the first deflection is $20 \mathrm{~cm}$ north of the mother hole, the second $20 \mathrm{~cm}$ east, the third 20 $\mathrm{cm}$ south and the fourth $20 \mathrm{~cm}$ west, thus forming a cross

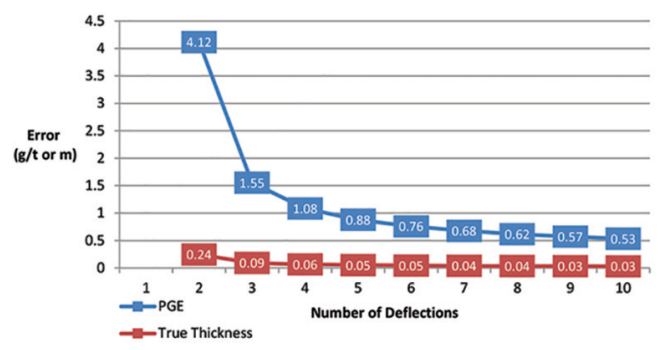

Figure $9-90 \%$ confidence error in estimate of the borehole grade and thickness from different numbers of deflections arrangement. Should there be more than four deflections then $40 \mathrm{~cm}$ is added north-east of the mother hole and so on.

The kriging weights for each deflection in the helical arrangement were examined in order to understand how kriging manages the clustered deflection data. The exercise was repeated using a number of different deflection arrangements, including a straight line (Figure 11). The grade and thickness estimates were compared so that the sensitivity of the estimate to different arrangements could be assessed:

1 The cross arrangement at $20 \mathrm{~cm}$ (the base case)

2 The cross arrangement at $500 \mathrm{~cm}$ separation

3 The cross arrangement at $1 \mathrm{~cm}$

4 No separation

5 A north-south line separated by $20 \mathrm{~cm}$ north, $40 \mathrm{~cm}$ north, and $20 \mathrm{~cm}$ south of the mother hole

6 An east-west line separated by $20 \mathrm{~cm}$ east, $20 \mathrm{~cm}$ west, and $40 \mathrm{~cm}$ west of the mother hole.

A $500 \mathrm{~m}$ (north) by $500 \mathrm{~m}$ (east) block (a standard size block used in areas outside of the channel sampling) was selected (Figure 12). The block chosen for test estimation has two surface boreholes located within it, which are approximately $220 \mathrm{~m}$ apart. These two holes are relatively closely spaced, the remaining boreholes being more typically spaced between $400 \mathrm{~m}$ and $500 \mathrm{~m}$ apart and spread around the test block. All of the boreholes within the test area intersected the UG2 Reef with three valid assayed deflections. The separation between boreholes is greater than the variogram range and therefore it is expected that the total kriging weight assigned to each borehole outside of the block to be estimated will not vary greatly.

The tests on the different spatial arrangements were conducted using the semivariogram shown in Figure 7. Table III shows the kriging weights applied in a block estimate using the standard cross arrangement at a variety of deflection separations.

The following observations were made:

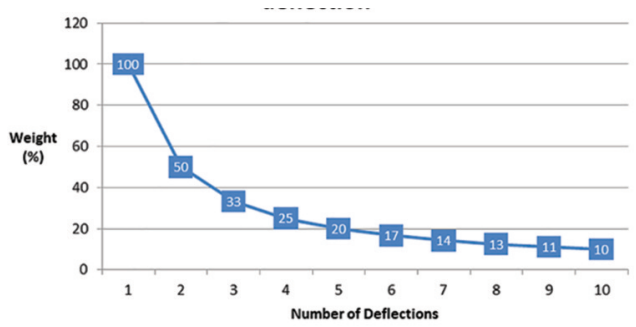

Figure 10-Borehole kriging weight of each deflection as a percentage of the total borehole kriging weight

\section{Cross East-West North-South}

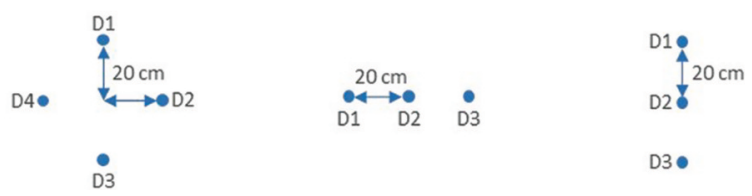

Figure 11-Illustration of various deflection arrangements used 


\section{Using short deflections in evaluating a narrow tabular UG2 Reef}

Using the standard $20 \mathrm{~cm}$ cross arrangement, the kriging weights applied to each deflection are almost the same. The holes within the block have slightly higher weighting on the estimate than those outside of the block. Holes outside the block have the same weight, being further away from the block than the
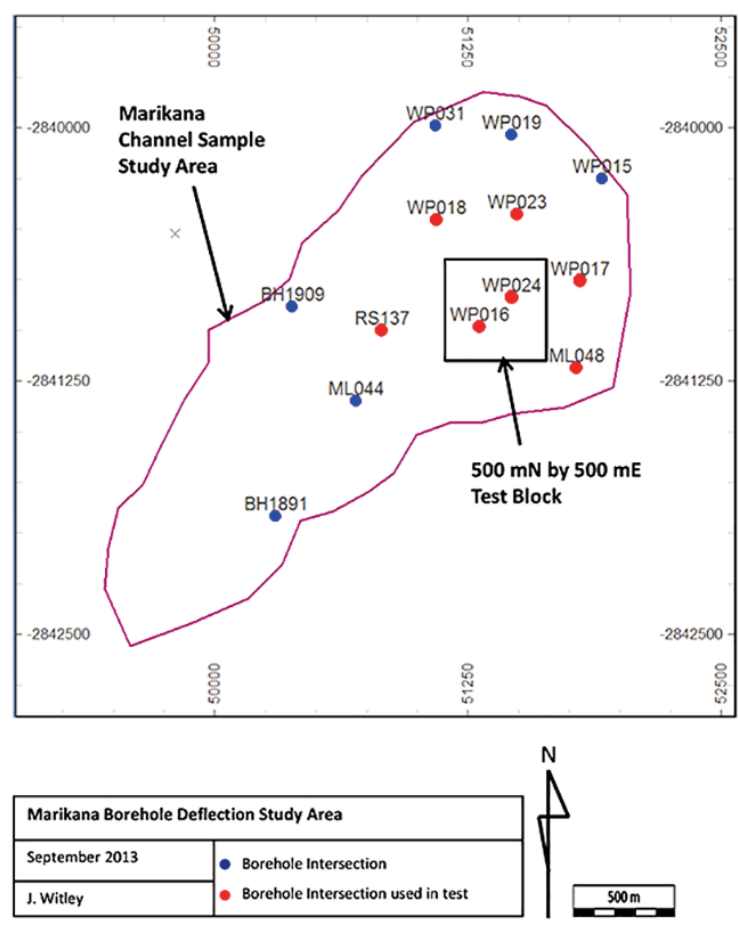

Figure 12-Location of borehole deflection study block in relation to borehole intersections and Marikana channel sample study area semivariogram range. Using the $1 \mathrm{~cm}$ cross arrangement (or if no separation is used at all), each deflection within a hole attracts the exactly the same weight

> Using the $500 \mathrm{~cm}$ cross arrangement, the second deflection in each case attracts approximately $8 \%$ lower kriging weight than the first and the third deflections for holes outside of the block. The difference in weights is likely caused by a principle known as 'shielding', whereby a sample in the same line of sight to the discretized point in the block to be estimated is given a lower weight than the other sample close by

> Using a north-south line arrangement introduces a slight shielding effect at $20 \mathrm{~cm}$ deflection spacing. The east-west arrangement gives the same results

> The average semivariance for each deflection within a borehole is 1.000 for those outside the block (they being further away from the block than the semivariogram range) and 0.994 and 0.995 for the two respective boreholes within a block. Insignificant changes to the total semivariance are seen whether deflections are spaced $1 \mathrm{~cm}, 20 \mathrm{~cm}$, or $500 \mathrm{~cm}$ from the mother hole, as there is no significant difference between $1 \mathrm{~cm}$ and $500 \mathrm{~cm}$ when related to the range of influence of $170 \mathrm{~m}$

> The estimated PGE grade for the block does not vary by more than $0.01 \mathrm{~g} / \mathrm{t} 4 \mathrm{E}$ with changes in the deflection arrangement.

The estimation weights assigned to deflections when different numbers of deflections exist for each hole were examined using the standard PGE grade semivariogram and the $20 \mathrm{~cm}$ separation cross arrangement for both ordinary kriging and inverse distance squared (Table IV).

Table III

Estimation weights for each borehole and intersection for the estimated block for the deflection arrangements tested

\begin{tabular}{|c|c|c|c|c|c|}
\hline \multirow[t]{2}{*}{ Borehole } & \multirow[t]{2}{*}{ Deflection* } & \multicolumn{3}{|c|}{ Estimation weight } & \multirow{2}{*}{$\begin{array}{l}\text { Sum of } \\
\text { weights }\end{array}$} \\
\hline & & $20 \mathrm{~cm}$ cross $/ 1 \mathrm{~cm}$ cross $/$ no spacing & $500 \mathrm{~cm}$ cross & $20 \mathrm{~cm}$ north- south line $/ 20 \mathrm{~cm}$ spaced east-west & \\
\hline WP018 & $\begin{array}{l}\text { D1 } \\
\text { D2 } \\
\text { D3 }\end{array}$ & $\begin{array}{l}4.7 \\
4.7 \\
4.7\end{array}$ & $\begin{array}{l}4.8 \\
4.4 \\
4.8\end{array}$ & $\begin{array}{l}4.7 \\
4.6 \\
4.7\end{array}$ & 14.1 \\
\hline WP023 & $\begin{array}{l}\text { D1 } \\
\text { D2 } \\
\text { D3 }\end{array}$ & $\begin{array}{l}4.7 \\
4.7 \\
4.7\end{array}$ & $\begin{array}{l}4.8 \\
4.4 \\
4.8\end{array}$ & $\begin{array}{l}4.7 \\
4.6 \\
4.7\end{array}$ & 14.1 \\
\hline WP017 & $\begin{array}{l}\text { D1 } \\
\text { D2 } \\
\text { D3 }\end{array}$ & $\begin{array}{l}4.7 \\
4.7 \\
4.7\end{array}$ & $\begin{array}{l}4.8 \\
4.4 \\
4.8\end{array}$ & $\begin{array}{l}4.7 \\
4.6 \\
4.7\end{array}$ & 14.1 \\
\hline WP024 & $\begin{array}{l}\text { D1 } \\
\text { D2 } \\
\text { D3 }\end{array}$ & $\begin{array}{l}5.0 \\
5.0 \\
5.0\end{array}$ & $\begin{array}{l}5.1 \\
4.8 \\
5.1\end{array}$ & $\begin{array}{l}5.0 \\
4.9 \\
5.0\end{array}$ & 15.0 \\
\hline WP016 & $\begin{array}{l}\text { D1 } \\
\text { D2 } \\
\text { D3 }\end{array}$ & $\begin{array}{l}5.0 \\
5.0 \\
5.0\end{array}$ & $\begin{array}{l}5.1 \\
4.8 \\
5.2\end{array}$ & $\begin{array}{l}5.0 \\
5.0 \\
5.0\end{array}$ & 15.0 \\
\hline RS137 & $\begin{array}{l}\text { D1 } \\
\text { D2 } \\
\text { D3 }\end{array}$ & $\begin{array}{l}4.7 \\
4.7 \\
4.7\end{array}$ & $\begin{array}{l}4.8 \\
4.5 \\
4.8\end{array}$ & $\begin{array}{l}4.7 \\
4.6 \\
4.7\end{array}$ & 14.1 \\
\hline ML048 & $\begin{array}{l}\text { D1 } \\
\text { D2 } \\
\text { D3 }\end{array}$ & $\begin{array}{l}4.7 \\
4.7 \\
4.7\end{array}$ & $\begin{array}{l}4.8 \\
4.4 \\
4.8\end{array}$ & $\begin{array}{l}4.7 \\
4.6 \\
4.7\end{array}$ & 14.1 \\
\hline
\end{tabular}




\section{Using short deflections in evaluating a narrow tabular UG2 Reef}

Table IV
Estimation weights for each borehole and intersection for both ordinary kriging and inverse distance squared
using variable numbers of deflection intersections

\begin{tabular}{|c|c|c|c|c|c|}
\hline \multirow[t]{2}{*}{ Borehole } & \multirow{2}{*}{ Deflection* } & \multicolumn{2}{|c|}{ Estimation weight } & \multicolumn{2}{|c|}{ Sum of weights } \\
\hline & & Ordinary kriging & Inverse distance squared & Ordinary kriging & Inverse distance squared \\
\hline WP018 & $\begin{array}{l}\text { D1 } \\
\text { D2 } \\
\text { D3 }\end{array}$ & $\begin{array}{l}5.1 \\
5.1 \\
5.1\end{array}$ & $\begin{array}{l}2.1 \\
2.1 \\
2.1\end{array}$ & 15.3 & 6.3 \\
\hline WP023 & $\begin{array}{l}\text { D1 } \\
\text { D2 } \\
\text { D3 }\end{array}$ & $\begin{array}{l}5.1 \\
5.1 \\
5.1\end{array}$ & $\begin{array}{l}2.2 \\
2.2 \\
2.2 \\
\end{array}$ & 15.3 & 6.6 \\
\hline WP017 & D1 & 9.5 & 2.7 & 9.5 & 2.7 \\
\hline WP024 & $\begin{array}{l}\text { D1 } \\
\text { D2 } \\
\text { D3 }\end{array}$ & $\begin{array}{l}5.4 \\
5.4 \\
5.4\end{array}$ & $\begin{array}{l}13.4 \\
13.4 \\
13.4\end{array}$ & 16.2 & 40.2 \\
\hline WP016 & $\begin{array}{l}\text { D1 } \\
\text { D2 }\end{array}$ & $\begin{array}{l}7.0 \\
7.0\end{array}$ & $\begin{array}{l}15.5 \\
15.5\end{array}$ & 14.0 & 31.0 \\
\hline $\mathrm{RS} 137$ & $\begin{array}{l}\text { D1 } \\
\text { D2 }\end{array}$ & $\begin{array}{l}6.6 \\
6.6\end{array}$ & $\begin{array}{l}1.6 \\
1.6\end{array}$ & 13.2 & 3.2 \\
\hline ML048 & $\begin{array}{l}\text { D1 } \\
\text { D2 } \\
\text { D3 } \\
\text { D4 }\end{array}$ & $\begin{array}{l}4.1 \\
4.1 \\
4.1 \\
4.1\end{array}$ & $\begin{array}{l}2.4 \\
2.4 \\
2.4 \\
2.4\end{array}$ & 16.4 & 9.6 \\
\hline
\end{tabular}

* Refer to Figure 11 for deflection number in the arrangement

Table $\mathrm{V}$

Estimation weights for each borehole lateral composite - ordinary kriging and inverse distance squared

\begin{tabular}{|l|c|c|}
\hline \multirow{2}{*}{ Borehole } & \multicolumn{2}{|c|}{ Estimation weight } \\
\cline { 2 - 3 } & Ordinary kriging & Inverse distance squared \\
\hline WP018 & 14.1 & 5.3 \\
WP023 & 14.1 & 5.7 \\
WP017 & 14.1 & 6.9 \\
WP024 & 14.6 & 35.3 \\
WP016 & 14.7 & 36.4 \\
RS137 & 14.1 & 4.0 \\
ML048 & 14.1 & 6.3 \\
\hline
\end{tabular}

Using ordinary kriging, boreholes with fewer deflections have a lower total estimation weight than those with more, but the individual weights assigned to each deflection are higher. In practice, the ordinary kriging system recognizes holes with more deflections and assigns higher confidence (weight) to them. At the same time a degree of declustering takes place. This is an important property of ordinary kriging when applied to multiple-deflection borehole grids. Although the weighting is quite small, the advantage of ordinary kriging over simple averaging or inverse distance techniques is that the borehole deflection intersection composites are declustered. At the same time, the total borehole is assigned a weight appropriate to the confidence in that hole by virtue of the number of deflections. Even with boreholes spaced further apart than the semivariogram range, ordinary kriging plays a part in the estimation when variable numbers of intersections occur for each borehole as the intersections are spatially correlated to each other.
Should inverse distance squared be used, the weights assigned to the individual deflections do not take into account the deflections a few centimetres away and no declustering takes place, each intersection being treated as a separate borehole. Intuitively, the ability of ordinary kriging to both decluster the data and assign confidence to a borehole on the number of deflections seems the most appropriate.

An alternative to estimating with individual deflection intersections is to estimate with lateral composites. The disadvantage of lateral composites is that the estimation weights cannot take into account the differing numbers of intersections. For the ordinary kriging example, the weights are almost the same for each lateral composite borehole. In the case of inverse distance squared, the weights differ widely between boreholes, with more than $70 \%$ of the weight being assigned to the two boreholes within the block.

In the case of inverse distance squared, the weights differ widely between boreholes, with more than $70 \%$ of the weight is assigned to the two boreholes within the block (Table V).

\section{Summary and discussion}

This study has highlighted the importance of multiple borehole intersections obtained through deflection drilling. The high nugget effect implies that the TBW-size half-core intersection sample is too small to cater for the high sample error. This constraint is overcome by drilling multiple deflections, which is a far more cost-effective way of obtaining a reliable borehole intersection than larger diameter drilling, with the added advantage of increased geological understanding.

Confidence in the grade and thickness of the UG2 Reef intersected in a borehole is greatly increased by intersecting the reef several times. At least three sampled intersections 


\section{Using short deflections in evaluating a narrow tabular UG2 Reef}

are required to gain reasonable confidence in the borehole. At least 50 boreholes, each with three or more deflections, are required to obtain a stable estimate of the nugget effect.

A number of important findings arose from the way in which multiple intersections are handled in the estimation procedure. Most notably:

- The kriged estimate is not sensitive to the spacing applied between the intersections at very small distances (tens of centimetres). The application of larger distances (several metres) should be avoided as the shielding effect causes the weights to be different for each intersection, when in practice they should be exactly the same for each intersection drilled from the same hole

> The cross arrangement currently used at Marikana is correct as it avoids the shielding effect experienced if the intersections are arranged in line. It is not known exactly what arrangement is actually achieved during drilling as the deflections are not surveyed; however, the cross arrangement obtains the most suitable result with the (untrue) assumption that deflection intersections are equally arranged around the mother hole

> Ordinary kriging effectively declusters the clusters of deflection intersections while attributing higher confidence to a borehole with a greater number of intersections. Intuitively, this is a desired effect

> The use of lateral composites does not take into account the higher confidence that one would wish to assign to a borehole with more intersections. If an inverse distance approach is used then lateral composites will avoid over-weighting of boreholes with many intersections, which would otherwise occur using individual deflection intersections. The authors consider that inverse distance is not a valid technique for high-nugget-effect deposits with clustered data.
Deflection drilling greatly assists in the identification of boreholes affected by geological disturbances such as faults and potholes. Techniques that examine the variability between intersections drilled from the same borehole help to identify data validation issues and subtle geological disturbances that might otherwise be overlooked. Multiple deflection drilling greatly reduces the risk associated with a borehole compared with that which would occur if a single intersection is used.

\section{Acknowledgements}

Lonmin Platinum kindly gave permission to use the data for this study and for publication of the paper.

\section{References}

CARRASCO, P.C. 2010. Nugget effect, artificial or natural? Journal of the Southern African Institute of Mining and Metallurgy, vol. 110, no. 6. pp. 299-305.

Clark, I. 1979. Practical Geostatistics, Elsevier. 129 pp.

CLARK, I. 2010. Statistics or geostatistics? Sampling error or nugget effect? Journal of the Southern African Institute of Mining and Metallurgy, vol. 110, no. 6. pp. 307-312.

HofFMANN, D. 2010. Statistical size analysis of potholes: an attempt to estimate geological losses ahead of mining at Lonmin's Marikana mining district. Proceedings of the 4th International Platinum Conference, Platinum in Transition 'Boom or Bust', Sun City, South Africa, 11-14 October 2010. Southern African Institute of Mining and Metallurgy, Johannesburg. pp. 97-104.

KRIGE, D.G. 1981. Lognormal-de Wijsian Geostatistics for Ore Evaluation, Monograph Series. South African Institute of Mining and Metallurgy, Johannesburg.

Matheron, G. 1971. The Theory of Regionalised Variables and its Applications. Cahier no. 5, Centre de Morphologie Mathématique de Fontainebleau. 211 pp.

Pitard, F.F. 1993. Exploration of the nugget effect. Geostatistics for the Next Century. Kluwer, Doordrecht, The Netherlands.

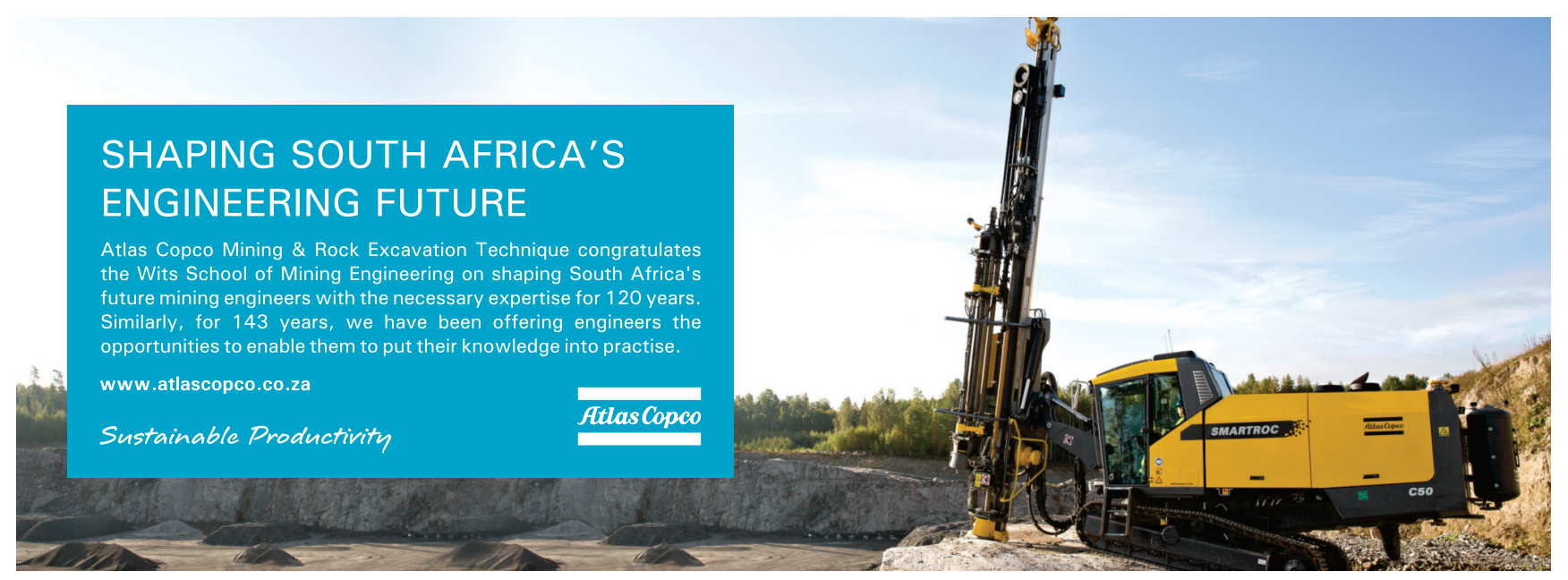



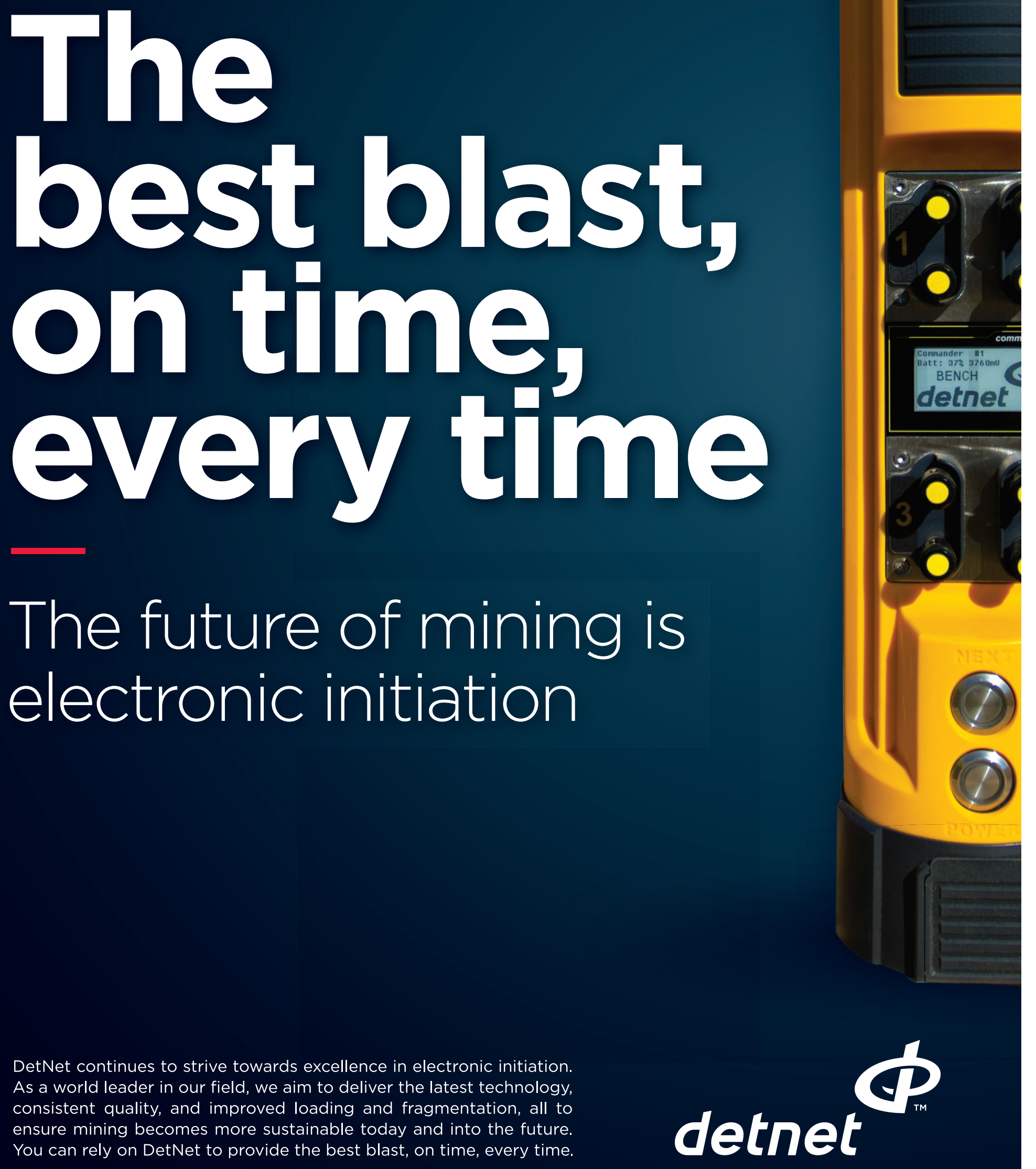

DetNet continues to strive towards excellence in electronic initiation As a world leader in our field, we aim to deliver the latest technology, consistent quality, and improved loading and fragmentation, all to ensure mining becomes more sustainable today and into the future. You can rely on DetNet to provide the best blast, on time, every time. 